\title{
28 Research Soure \\ Testing the Contextual Interaction Theory in a UHC pilot district in South Africa
}

Janet Michel ( $\nabla$ janetmichel71@gmail.com )

Swiss TPH: Schweizerisches Tropen- und Public Health-Institut https://orcid.org/0000-0002-8412219X

\section{Nthabiseng Mohlakoana}

University of Twente: Universiteit Twente

\section{Till Bärnighausen}

Harvard University HSPH: Harvard University T H Chan School of Public Health

\section{Fabrizio Tediosi}

University of Basel: Universitat Basel

\section{David Evans}

World Bank

\section{Di McIntyre}

University of Cape Town

\section{Hans T. A Bressers}

UT: Universiteit Twente

\section{Marcel Tanner}

University of Basel: Universitat Basel

\section{Methodology}

Keywords: Contextual Interaction Theory, Leadership, Motivation, Information, Resources, Context, Interactions. Implementation, policy-practice gaps

Posted Date: October 21st, 2020

DOI: https://doi.org/10.21203/rs.3.rs-93700/v1

License: (a) (i) This work is licensed under a Creative Commons Attribution 4.0 International License. Read Full License 


\section{Abstract}

Background: World-wide, there is growing universal health coverage (UHC) enthusiasm. The South African government began piloting policies aimed at achieving UHC in 2012. These UHC policies have been and are being rolled out in the ten selected pilot districts. Our study explored policy implementation experiences of 71 actors involved in UHC policy implementation, in one South African pilot district using the Contextual Interaction Theory (CIT) lens.

Method: Our study applied a two-actor deductive theory of implementation, Contextual Interaction Theory (CIT) to analyse 71 key informant interviews from one National Health Insurance (NHI) pilot district in South Africa. The theory uses motivation, information, power, resources and the interaction of these to explain implementation experiences and outcomes. The research question centred on the utility of CIT tenets in explaining the observed implementation experiences of actors and outcomes particularly policypractice gaps.

Results: All CIT central tenets (information, motivation, power, resources and interactions) were alluded to by actors in their policy implementation experiences, a lack or presence of these tenets were explained as either a facilitator or barrier to policy implementation. This theory was found as very useful in explaining policy implementation experiences of both policy makers and facilitators.

Conclusion: A central tenet that was present in this context but not fully captured by CIT was leadership. Leadership interactions were revealed as critical for policy implementation, hence we propose the inclusion of leadership interactions to the current CIT central tenets, to become motivation, information, power, resources, leadership and interactions of all these.

\section{Contribution To The Literature}

- Empirical research discloses implementation as a significant impediment to change. Understanding what facilitates or hinders implementation is critical as many countries strive towards universal health coverage: these findings advance our understanding of how to effectively implement UHC policies in a context similar to South Africa

- Policy implementation is a complex process. A theoretical framework is a lens through which policy implementation can be understood. The literature is awash with many implementation theories. Understanding implementation theories that capture implementation experiences of actors in a particular context aids in reducing policy-practice gaps. Our study has demonstrated the utility of CIT in UHC policy implementation context-South Africa

- Contextual Interaction Theory was developed in a water governance and policy implementation context. To the best of our knowledge, this is one of the first studies that applied CIT in a UHC policy implementation context, assessing its utility and identifying any short-comings. We identified leadership as a critical factor, actors repeatedly alluded to as affecting implementation. This factor however is not explicitly identified as a central tenet in $\mathrm{CIT}$, hence our proposal to include this and 
improve the utility of CIT in contexts like South Africa. Adding leadership to these central tenets is our proposal to make CIT useful in contexts similar to South Africa. We propose the central tenets to become motivation, information, power, resources, leadership and interactions of all these.

- Contexts matter a lot in implementation. Theoretical frameworks are important road maps in policy implementation and analysis. CIT is a simple but very useful theory and framework that condenses reality into less detailed but informative elements (information, motivation, power, resources, interactions of these). Our contribution to literature is an adapted CIT theory that fully captures policy implementation experiences of actors in a UHC context.

\section{Background}

Empirical research discloses implementation as a significant impediment to change [1, 2]. This paper contributes to implementation studies by testing an implementation theory, Contextual Interaction theory in a new domain, health. Our study explored policy implementation experiences of 71 actors involved in universal health coverage (UHC) policy implementation, in one South African pilot district using the CIT lens.

South Africa is the focus of this study because the South African government began piloting policies aimed at achieving UHC in 2012. Policies aimed at achieving UHC have been and are being rolled out in the selected 10 pilot districts. World-wide, there is growing UHC enthusiasm at global and national levels [3]. Almost everyone world-wide believes that no-one should be pushed into poverty for accessing health care. Many also believe in a world in which everyone can live healthy productive lives regardless of who they are or where they live. This outcome will depend to a great extent on how UHC policies are and will be implemented. For example, the South African Ministry of health`s role in providing guidance has been characterized by good policies without equivalent emphasis on implementation, monitoring and assessment of these policies through-out the system [4]. When filtering public policy through the circumstance of reality, it is important to bear in mind that intention may not correspond with outputs and outcomes [2]. In 2017, the South African NHI pilot phase, health systems strengthening came to an end, though health strengthening initiatives and improvements of service delivery platforms continue to be implemented [5]. Many lessons have been learnt during the past five years including implementation bottlenecks such as supply chain, infrastructural and resource challenges and underspending of conditional grants $[3,6]$. In addition, there is a call that it is essential that once data and information from pilot districts becomes available, it should be fully utilized, evaluated and results be published to allow for government and public to engage with the process as well as foster accountability [7].

Defining Implementation

To understand implementation, it is important to define the concept as used in the scope of this study. Pressman and Wildavsky [1] defined implementation as to carry out, accomplish, fulfil, produce, complete a policy. Mazmanian and Sabatier [8] define implementation as the carrying out of a basic policy decision. O'Toole [9] defines implementation as what develops between establishment of an apparent 
intention on the part of government to do something or to stop doing something and the ultimate impact in the world of action. For the purpose of this study we define policy as translating public policy intention into results [2].

Policy implementation is a complex process incumbent upon a number of factors. It is important to not only understand why policies succeed but also why they fail [10]. Many scholars find it useful to treat implementation as a distinctive point for analysis within the policy process with an ability to shed light on the whole $[1,11,12]$.Three generations of implementation theories shape the policy implementation field. The first generation, illustrated by the work of Pressman and Wildavsky is also known as top-down. Researchers analysed the implementation of a regional employment programme and came to the conclusion that amongst other things, implementation failed due to poor policy planning. This generation assumed that implementation happens as a pure application of earlier decisions and consisted of solitary case studies featuring negative reports of the way governments implement their own programmes[2]. Policy making was assumed to be automatically followed by successful policy (14). This generation of theories is also likened to what Elmore [13] describes as forward mapping. Forward mapping assumes that implementation is controlled from the top and stresses factors that emphasize control such as funding formulas and authority relationships. The closer one is to the source of policy, the greater their influence and authority [13]. According to Goggin et al (ref), the first-generation studies have been criticized for being a theoretical, case specific and noncumulative and overly pessimistic. They however have been valuable in shifting the focus and showing how a law becomes a programme and demonstrating the complex and dynamic nature of implementation among others [9].

The second generation theories, according to Sabatier [14] started in the late 1970s to early 1980 s, where the bottom uppers started with an analysis of the multitude of actors who interact at an operational (local ) level on a particular issues. The focus was on strategies pursued by various actors with the aim of fulfilling their objectives. Efforts were focused on setting out to record and illustrate the complexities of implementation and to show that just because a policy exists, does not guarantee that it will be implemented [14]. The bottom up approach emphasizes the role of the smallest actor in the implementation process all the way to the top [13]. Lipsky work on Street Level Bureaucrats [15] is one bottom up example. The study illustrates how civil servants at lower levels implement policies according to what they think is best and not according to directives. This is not a result of defying authority or going against rules set by those at the top, but it is a way in which actors at the bottom cope with implementation of policies that are otherwise out of their scope because of the way they are planned [15]. Walker and Gilson used the street level bureaucrat's framework in South Africa, investigating, "how a group of nurses in primary care clinics experienced the implementation of free care and other South African national health policies post 1996." They too, came to a conclusion that, civil servants faced with policy implementation use their discretion based on their views and values [16]. After years of debate between proponents of top down and bottom up approaches, most researchers concede the merits of both perspectives with several scholars recommending a synthesis of the two into a unifying model $[9$, $11]$. 
Van Meter and Van Horn [17] highlight the systems model of implementation" in which they show that there is more to what influences the performance of a programme or a policy that separate factors. The separate factors include policy standards, resources, support for policies in a political environment, economic and social conditions, characteristics of implementing agencies, communication of policy standards incentives to promote compliance and policy dispositions of implementing officials. These factors highlight the importance of context in policy implementation process leading us to the third generation of implementation research and how it combines both top down and bottom up approaches. The third-generation implementation researchers see implementation as an ongoing process, regardless of result[18]. Goggin et al [9] promote a third generation of research to illuminate the variability within implementation scenarios using more stringent scientific methods. Ad-hoc explanations do not capture the essence of why policy implementation fails, are often incomplete and insufficient in telling and explaining the whole story [11] Implementation theory and research have outgrown the search for a single theory of implementation and have entered a new era that recognizes multiple theories appropriate to various implementation research questions [19].

Justification of Contextual Interaction Theory

Contextual Interaction Theory (CIT) is a third generation theory [9] developed in the Netherlands during the late 1990 s and has been applied in several studies $[2,20]$ but not widely used in the health policy domain. CIT is relatively simple, with broad applicability as it analyses the very core of implementation: the motivation, information, resources and power of target and implementer. CIT emphasizes the policy target and implementer, whether they exist as local implementers or higher-level administrators. A useful theory must condense reality into less detailed but informative elements [2]

Scharpf (23) writes that overly parsimonious theories ignore either actors or institutions in pursuit of the other. CIT is parsimonious, distilling a sea of options for implementation variables into core variables of motivation, information, resources and power. These variable are not arbitrarily chosen as three important variables among others but because they have high explanatory power and exist at the core of interaction process $[2,11]$. CIT is therefore a deductive and realistic approach that allows implementation to be effectively analysed [2].In implementation science, theoretical approaches serve three main purposes: to describe and or guide the translation of research into practice-process models, to understand or explain factors that influence policy implementation (implementation theories) and to evaluate implementation (evaluation frame works) [22]. CIT utility has been proven in all three areas elsewhere [2, 11, 23, 24]

Description of CIT

The theory focuses on motivation, information, power, resources and interactions of these. CIT also allows this study to focus not only on CIT variables but also context, structural and outer. CIT has been used in the South African context before[18]. Applying CIT to analyse UHC policy implementation is a new domain. Based on the amount of information the actors have on policy, their level of motivation, the amount of resources they have to implement and the amount of power they have to mobilize needed resources and various interactions of these, a policy can be successfully implemented. In this study we 
analysed how much Information, Motivation, Power, and Resources they had with regards to UHC policies they were tasked to implement. We also analysed the data inductively.

One of CIT's key assumption is that factors influencing implementation are interactive. The influence of any factor whether positive or negative depends on the particular context. The theory distinguishes a set of core constructs or concepts related to the actors involved which jointly contribute to implementation. Core constructs are;

\section{Motivation}

The level of importance the actors place on a policy and the degree to which policy contributes to their goals and objectives affects implementation. If actors have low motivation, they may ignore implementing the policy. Examining motivation helps to understand the perspectives of implementers, their belief system, value priorities and perception of the importance and magnitude of specific problems often revealing root causes of implementation barriers [20].

\section{Information}

Successful policy implementation requires that those involved have sufficient information including technical knowledge of the matter at hand, levels and patterns of communication between actors. For example, do those responsible for implementation actually know with whom they should be working and who the policy should benefit? Do they know which department is assigned to lead the implementation and how the programme will be monitored? How is information and communication between actors coordinated? Have guidelines been developed and are they readily available? [11, 20].

\section{Power}

Who is empowered to implement policy and to what degree? Power may derive from formal sources such as a legal system e.g. appointment or from informal sources such as charisma or being an elderly.

\section{Resources}

Having adequate resources for the intended action is important for actors to realize policy implementation goals. Resources provide the capacity to act [25]. The relevance and availability of resources influence the actors motivation which in turn influences the whole policy implementation process [23].

\section{Interactions}

interactions predict the level of collaboration among and between actors which in turn influence policy implementation. They must be considered to further analyze barriers to implementation. These interactions can take different forms from cooperation, passive cooperation, forced cooperation, opposition or joint learning. In turn actors collaboration depends on how they perceive the problem being addressed as a priority, how convinced they are that there is an acceptable solution, that taking action 
now is in own best interest and if they have implementing capacity [11, 20]. Specifying the above constructs facilitates the development of tools to measure the level at which each of the core construct contributes or hinders implementation [20]. These central CIT tenets guided our analysis and interpretation of findings in this study.

\section{Methods}

\section{Study Aim}

The study aimed at tracking NHI policy implementation process through the engagement of policy makers and policy implementers in order to explore, identify and describe why and how policy-practice discrepancies come about in UHC context.

\section{Research setting and sampling}

Ten pilot districts were identified by the Department of Health and selected as National Health Insurance $(\mathrm{NHI})$ pilot sites. The National Department of Health $(\mathrm{DoH})$ selected these sites based on poor performance on key health indicators like high maternal and child mortality rates [3]. UNITAS purposively selected three out the ten selected NHI pilot districts in South Africa. A case study design was used for this research. A case study design is defined as an empirical inquiry that investigates a phenomenon within its real-life context [26]. This study is situated in only one of the three districts, district X (name withheld for anonymity reasons). The case was the district (X), conveniently selected as the only $\mathrm{NHI}$ pilot district in that province at the time. Managerial support and willingness to participate in the study also guided site selection.

\section{Study design and data collection}

A qualitative, exploratory case study design was utilized. We tracked policy implementation aimed at achieving Universal Health Coverage in one pilot district in South Africa from 2011-2015. Data was collected during three phases 2011-2012 (Contextual mapping), 2013-2014 (Phase 1) and 2015 (Phase 2). A theory of change (TOC) approach was followed to explore universal health coverage policy implementation experiences. TOC is a theory of how and why initiatives work [27]. Theory of change describes assumptions actors have, explains steps and activities they take to achieve goals and connections between these activities and the policy outcome [27]. Semi-structured in-depth interviews were held with participants using a standard interview guide. Participants ranged from provincial, district, sub-district and facility actors involved in policy implementation. No patients were involved since their role in policy implementation is limited. The duration of each interview varied from 2-3 hours. Two researchers at every occasion, conducted the interviews in English. All participants were qualified professionals who had no problems understanding or responding in English. Full Ethical approval for the study was granted by the University of KwaZulu-Natal Biomedical Research Ethics Committee; REF BE197/13. Support letters were also provided by the provincial and district offices in our study site. 


\section{Data analysis}

All interviews were audio-recorded. All participants gave informed and signed consent and were free to withdraw from the study at any time. An iterative, inductive and deductive data analysis approach guided by Contextual Interaction theory was utilized. Transcripts were coded with the aid of MAXQDA2018. Trustworthiness criteria were used to evaluate rigour for this study[28]. Trustworthiness concepts included dependability, credibility, confirmability and transferability. To ensure dependability we described data collection process in detail and two researchers experienced in qualitative methods, kept reflexive individual journals through-out data collection and analysis. Debriefing after interviews was done daily in the field. The two researchers further analysed the data independently before reaching consensus under the supervision of an experienced qualitative researcher. To ensure confirmability findings were discussed with supervisors and co-authors experienced in the field, and their responses were incorporated. To enhance transferability, participants, context and process of analysis have been described in detail[28]. We achieved data saturation [29] and data source triangulation, through interviewing actors from different levels of the health system.

Actor description: In a UHC pilot site the following actors are present [24]. See Table 1 below; Justification of two actor scenario

Table 1

Study actor description in general

\begin{tabular}{|llll|}
\hline $\begin{array}{l}\text { Policy Maker } \\
\text { Actors }\end{array}$ & Linking actor & Implementing actors & Target actors \\
\hline $\begin{array}{l}\text { National DOH } \\
\text { Provincial DOH }\end{array}$ & $\begin{array}{l}\text { NGOs providing } \\
\text { training }\end{array}$ & $\begin{array}{l}\text { District, subdistrict and PHC } \\
\text { staff }\end{array}$ & $\begin{array}{l}\text { Patients and } \\
\text { communities }\end{array}$ \\
\hline
\end{tabular}

It is worth mentioning that a multi -actor scenario in health policy evaluation is possible and appropriately suitable in cases of assessing successful policy implementation, involving policy maker, policy implementer, partners and target actors in this case patients. The focus of our study was to understand how policy-practice gaps come about, hence our focus is on two actors, policy maker and policy implementer instead. We therefore tested the viability of a two-actor model-policy makers at Provincial level and policy implementers (district, subdistrict, facility actors)

\section{Study actors}

The focus of our study was to understand policy practice gap hence our two actors are policy maker and policy implementer leaving out linking and target actors as they did not play an active role in UHC policy implementation. See Table 2 below: 
Table 2

Study actor description used in our study

\begin{tabular}{|ll|}
\hline Policy Maker Actors & Implementing actors \\
\hline National DOH & District Managers and District staff \\
Provincial DOH & Subdistrict managers and staff \\
& PHC facility staff
\end{tabular}

\section{Research participants}

71 key informants were involved. See description in Table 3 below;

Table 3

Overview of key informants, research phase, role and where they worked (health system level)

\begin{tabular}{|c|c|c|c|c|c|}
\hline $\begin{array}{l}\text { Health } \\
\text { System } \\
\text { Level }\end{array}$ & Role & $\begin{array}{l}\text { Contextual } \\
\text { mapping }\end{array}$ & $\begin{array}{l}\text { Round } \\
1\end{array}$ & $\begin{array}{l}\text { Round } \\
2\end{array}$ & Total \\
\hline Provincial & $\begin{array}{l}\text { Policy maker -making sure NHI policies are } \\
\text { carried out }\end{array}$ & 1 & 1 & 1 & 3 \\
\hline District & $\begin{array}{l}\text { Policy implementers ranging from district } \\
\text { manager, programme managers, district } \\
\text { clinical specialist team, Emergency rescue } \\
\text { service manager and PHC supervisors with } \\
\text { policy implementation responsibilities } \\
\text { including the PHC supervision manual }\end{array}$ & 1 & 5 & 4 & 10 \\
\hline Subdistrict & $\begin{array}{l}\text { Policy implementers at subdistrict level } \\
\text { ranging from CEOs managers, nurses and } \\
\text { doctors implementing policies aimed at UHC } \\
\text { as well as providing direct patient care }\end{array}$ & 3 & 12 & 8 & 23 \\
\hline $\begin{array}{l}\text { PHC } \\
\text { facility }\end{array}$ & $\begin{array}{l}\text { Policy implementers including operational } \\
\text { managers and staff in PHC facilities } \\
\text { implementing policies aimed at UHC as well } \\
\text { as providing direct patient care }\end{array}$ & - & 19 & 16 & 35 \\
\hline Total & & 5 & 37 & 29 & 71 \\
\hline
\end{tabular}

\section{Results}

Detailed findings of study were published in papers $[10,30,31] 2$ and it is beyond the scope of this paper to present them here. A summary of findings from the overall study with regards to CIT tenets are presented. See Table 4 below; 
Table 4

Summary of Findings

\begin{tabular}{|c|c|c|}
\hline $\begin{array}{l}\text { Core CIT } \\
\text { construct }\end{array}$ & Policy maker & Implementer \\
\hline Information & $\begin{array}{l}\text { Fully informed and aware of } \\
\mathrm{NHI} \text { policies and intended } \\
\text { benefits } \\
+++\end{array}$ & $\begin{array}{l}\text { District and senior staff aware but many frontline } \\
\text { actors have little understanding of their roles[10] }\end{array}$ \\
\hline Resources & $\begin{array}{l}\text { Some actors had access to } \\
\text { budgets } \\
+\end{array}$ & $\begin{array}{l}\text { District, subdistrict and facility staff cited lack of } \\
\text { human, material and infrastructural resources to fully } \\
\text { implement policies[10,30]. }\end{array}$ \\
\hline Motivation & $\begin{array}{l}\text { Some actors were new } \\
\text { appointees to drive the } \mathrm{NHI} \\
\text { policy implementation and } \\
\text { were generally motivated } \\
++\end{array}$ & $\begin{array}{l}\text { District and subdistrict actors were demotivated by } \\
\text { dysfunctional systems particularly supply chain [10, } \\
30] \text {. } \\
\text { Facility staff were demotivated due to lack of } \\
\text { resources, dysfunctional systems including employee } \\
\text { performance and management systems and lack of } \\
\text { support from above }[10,30] \\
\text { Facility staff were demotivated due to being caught } \\
\text { in between with pressure from both patients and } \\
\text { supervisors[10,30] } \\
\text { Facility actors were demotivated due to longstanding } \\
\text { problems that do not get resolved[10,30] }\end{array}$ \\
\hline Power & $\begin{array}{l}\text { Some actors had access to } \\
\text { budgets and power to } \\
\text { appoint personnel } \\
\text { Other functions are only } \\
\text { advisory in nature e.g. NHI } \\
\text { project Manager } \\
+\end{array}$ & $\begin{array}{l}\text { District, subdistrict and facility staff all cited no } \\
\text { power to appoint staff }[10,30] \\
\text { Facility actors have no access to budgets[10,45] } \\
\text { District and subdistrict Managers cited having limited } \\
\text { power and financial delegations }[10,45] \\
\text { According to Elmore funding affects implementation } \\
\text { [13] }\end{array}$ \\
\hline
\end{tabular}




\section{Core CIT Policy maker Implementer \\ construct}

Interactions Actors were housed in one building and had regular meetings though many posts vacant

$+$
PHC supervision not frequent enough $[10,30]$

PHC supervisor not able to solve facility challenges[10, 30].

$\mathrm{PHC}$ supervision seen as policing and not supportive[10, 31]

National core standards failing facility staff for issues beyond their control[10,30]

According to Elmore, authority relationships affect implementation[13]

negative

+present

++ high levels

+++ very high levels

\section{Discussion}

This paper applied a two actor CIT theory to analyse 71 interviews from a South African NHI pilot site. This paper contributes to implementation studies through the testing of the contextual interaction theory in a UHC setting, not done before, to the best of our knowledge. The study aimed to depict how actor characteristics (Information, Power, Motivation) influence UHC policy implementation process in one pilot district in South Africa [10]. To a certain extend the study combined first generation and third generations of research approaches. The first generation is illustrated by identifying policy-practice gaps as a result of top down UHC policies[10, 30]. The second generation by initiatives and decisions taken by the frontline actors. The third generation of implementation research is illustrated by using CIT factors to understand how the policy-practice gap comes about. We also expand the theory by adding one more core variable: leadership to information, motivation, resources and power [31]. Leadership Interaction is defined as an occasion when two or more people communicate with or react to each other [32] particularly between senior and junior actors including supervisor-supervisee relationships

There were discrepancies with regards to all CIT tenets when policy makers are compared with policy implementers [10]. See Figs. 1, 2 and 3 above. The amount of information, power, resources are higher for policy makers, at the top (province) as compared to the implementing actors[10]. Findings also replicated interactions of information, motivation, power and resources as well as human factors perception, response and motivation[10,30]. PHC supervision and lack of support from the top was repeatedly cited 
as a challenge by implementing actors $[10,30,33]$. The tenet Leadership is not explicitly represented in CIT [34]. This study also serves to illustrate CITs flexibility to contexts by adding a fourth variable, namely leadership interactions, to the CIT core variables, motivation, information, resources, power and interactions of these.

Adding and highlighting a fourth construct leadership (meaning supervisor supervisee interactions)

This section introduces a new variable leadership into the four CIT core construct framework. In all the analysed cases for this study and published papers [10,30,31,33], it became apparent that ignoring leadership in policy implementation could leave out important contributions that illustrate how leadership influences the implementation process. The critical roles of leadership, the human factors and our proposal to adapt the CIT tenets to (information, motivation, power, resources, leadership and interaction of these) are discussed. See Fig. 4 below;

\section{Leadership Definition}

Leadership Interactions are defined as an occasion when two or more people communicate with or react to each other [32] of particular importance in our study is the formal relationship between managers and subordinate actors including supervisor-supervisee relationships. In the context of our study, meaningful leadership interactions are formal relationships in the health system, implementing actors can fall back on for support, role clarification, motivation and problem solving. Effective leaders have decision making power and financial delegations to unlock resources and solve existing problems and challenges impeding implementation [31, 35]. There is a two-way open communication where leadership is present. Leaders have a vision, inspire subordinates and align and mobilize resources to ensure successful policy implementation[35]. The chronic resources challenges and lack of support cited by implementing actors' points at leadership gaps $[10,30,36]$. Negative leadership interactions were revealed as non-responsive and blame and punishment of subordinates whenever things went wrong. That in turn created a chain of responses by implementing actors, the human factors in the system, creating an added layer of implementation barriers [10].

Policy implementation failure has been repeatedly associated with a lack of leadership [4, 19]. According to Meyers and Dillon 1999, something happens within the organization that can either halt the process of implementation or speed it on its way. This something seems to be associated with organizational leadership $[10,19,31]$

Figure 4 about here

\section{Limitations and Strengths}

One of the limitations is that our study was carried out in only one pilot district though our findings concurred with studies from other pilot sites. Another drawback is that UHC policies were the focus of our study and so we did not touch on other national policies that were also in implementation at the same time. UNITAS on the other hand, was one of the first systems set up to document, track and monitor UHC 
policy implementation in a low- and middle-income countries. That way, utilizing a theory of change approach, engaging both policy makers and policy implementers, the experiences of these actors could be captured over time- 5 years. Empirical examples of challenges that hindered implementation and factors that facilitated success could thus be captured providing a wholistic picture of what goes on in a South African UHC policy implementation context. On the whole, the qualitative methodology in conjunction with $\mathrm{CIT}$ analytic framework, allowed us to answer the why and how questions of policy implementation thereby getting deeper insights. Finally, to the best of our knowledge the utility of CIT has not been tested in a UHC coverage context before-making our study one of the first ones to assess CIT utility in a low-to middle-income UHC context.

\section{Conclusion: Case for Leadership as an additional CIT tenet}

CIT proved to be a useful framework for analysing data from a UHC implementation site. The CIT central tenets Information, Motivation, Power, Resources and Interactions were observed, alluded to by all actors and their utility in policy implementation were replicated in our study. One aspect that dominated the South African policy implementation context was leadership. This leadership gap has been revealed in literature before as an impediment to successful policy implementation [35, 37-40]. Our study findings repeatedly pointed at this gap. Leadership was associated with information, motivation, resources, power and interactions of these. Leaders are not satisfied with the status quo [37]. Our research revealed chronic staff shortages, material, human and infrastructure, leaking roofs, unrepaired toilets, supply chain woes, supervision challenges, non-responsive leadership, long waiting lines [10,30,31]. There seems to be a lack of people with visions of what ought to be, people who can inspire others to strive forwards, motivating them, aligning and mobilizing resources to ensure successful implementation [37]. An ideal clinic is a clinic with good infrastructure, adequate staff, adequate medicine and supplies, good administrative processes and adequate bulk supplies that use applicable clinical policies, protocols, guideline as well as partner and stakeholder support, to ensure the provision of quality health care services to the community [41]. Leadership in implementation is key and critical in as far as it affects resource availability, motivation and information. Most of the actors' motivation was affected by longstanding unresolved challenges confirming the leadership gap. Leaders inspire, leaders motivate, leaders communicate and leaders align and mobilize resources to ensure effective policy implementation. To accurately reflect the SA UHC context, we propose adding leadership as a core CIT tenet to become: Information, Power, Motivation, Resources, Leadership and Interactions of all these. In order to achieve UHC, a shift from disease specific to a system wide approach is required. Without a functional basic health care system, all health and its related targets are in jeopardy [42]. For this to happen, leadership is needed. Current evidence points to gaps between policy and practice without necessarily explaining how this comes about $[43,44]$. The importance of leadership in policy implementation has been revealed by our study, hence it cannot be overemphasized.

\section{Abbreviations}

CIT. Contextual Interaction Theory 
UHC Universal health coverage

SA. South Africa

\section{Declarations}

\section{Ethics approval and consent to participate}

Full Ethical approval for the study was granted by the University of KwaZulu-Natal Biomedical Research Ethics Committee; REF BE197/13. Support letters were also provided by the provincial and district offices in our study site.

\section{Consent for publication}

Not Applicable

\section{Availability of data and materials}

Data and material from this study cannot be provided publicly due to ethical obligations to protect anonymity of participants. As stipulated in the participants "informed consent form," data access is limited to members of UNITAS research team. For further information related to data, please contact the corresponding author.

\section{Competing interests}

Authors declare no competing interests

\section{Funding}

This research was funded through the European Commission`s Seventh Framework Programme (FP7-CPFP-SICA, grant agreement number 261349)

Acknowledgements: None

\section{Author contributions}

JM had the initial concept and NM, TB, FT, DE, AM, HTAB, and MT wrote and contributed to further drafts. All authors met the ICMJE criteria and approved the final draft

\section{References}

1. Pressman JL, Wildavsky, Aaron. Implementation: 1973. 
2. Owens KA. Understanding how actors influence policy implementation: a comparative study of wetland restorations in New Jersey, Oregon, The Netherlands and Finland. Enschede: University of Twente [Host; 2008.

3. Fusheini A, Eyles J. Achieving universal health coverage in South Africa through a district health system approach: conflicting ideologies of health care provision. BMC Health Serv Res 2016;16. https://doi.org/10.1186/s12913-016-1797-4.

4. Coovadia H, Jewkes R, Barron P, Sanders D, Mclntyre D. The health and health system of South Africa: historical roots of current public health challenges. The Lancet. 2009;374:817-34. https://doi.org/10.1016/S0140-6736(09)60951-X.

5. National Health Insurance - NHI n.d. http://www.health.gov.za/index.php/nhi (accessed January 30, 2019).

6. NHI Pilot Phase progress; Health Conditional Grants: report by Minister of Health | PMG 2014. https://pmg.org.za/committee-meeting/17036/ (accessed January 30, 2019).

7. Health-Reform-Brief-1-July-2013-NHI-Pilots.pdf n.d.

8. Mazmanian DA, Sabatier PA. Implementation and Public Policy n.d.

9. Goggin ML, Lester JP, O’Toole LJ. Jr. Implementation Theory and Practice: Toward a Third Generation. 1990.

10. Michel J, Chimbindi N, Mohlakoana N, Orgill M, Bärnighausen T, Obrist B, et al. How and why policypractice gaps come about: a South African Universal Health Coverage context. J Glob Health Rep. 2019;3:e2019069. https://doi.org/10.29392/joghr.3.e2019069.

11. Bressers Hans. Implementing Sustainable Development: How to Know What Works, Where, When and How." Pp. 284-318. vol. Cheltenham. Cheltenham; 2004.

12. Hill MJ, Hupe PL. Implementing public policy: governance in theory and practice. London; Thousand Oaks: Sage; 2002.

13. Elmore RF. Backward Mapping: Implementation Research and Policy Decision. Polit Sci Q n.d.;94:601-14.

14. Sabatier PA. Top-down and bottom-up approaches to implementation research: A critical analysis and suggested synthesis. J Public Policy. 1986;1:21-48.

15. Lipsky M, Street-Level, Bureaucracy. Dilemmas of the Individual in Public Services. New York: Russell Sage Foundation; 1980.

16. Walker L, Gilson L. "We are bitter but we are satisfied": nurses as street-level bureaucrats in South Africa. Soc Sci Med 1982. 2004;59:1251-61. https://doi.org/10.1016/j.socscimed.2003.12.020.

17. Van Meter D, Van Horn CE. The policy implementation process: A conceptual framework. 6 1975;4:445-88.

18. thesis_N_Mohlakoana.pdf n.d.

19. Mischen PA. Intraorganizational Implementation Research: Theory and Method. J Public Adm Res Theory. 2006;17:553-66. https://doi.org/10.1093/jopart/mul027. 
20. Spratt K. Policy Implementation Barriers Analysis: Conceptual Framework and Pilot Test in Three Countries 2009:48.

21. Scharpf FW Games Real Actors Play: Actor-Centered Institutionalism in Policy Research. Boulder Colo Westview Press 1997.

22. Nilsen P. Making sense of implementation theories, models and frameworks. Implement Sci. 2015;10:53. https://doi.org/10.1186/s13012-015-0242-0.

23. de Boer C, Bressers H. Complex and Dynamic Implementation Processes 2011:246.

24. Nthabiseng Mohlakoana. Energy Policy A Dynamic Actor Interaction Nthabiseng Mohlakoana Implementing the South African Free Basic Alternative Energy Policy A Dynamic Actor Interaction 2014.

25. Oboirien K, Harris B, Goudge J, Eyles J. Implementation of district-based clinical specialist teams in South Africa: Analysing a new role in a transforming system. BMC Health Serv Res. 2018;18:600. https://doi.org/10.1186/s12913-018-3377-2.

26. Press Academia. Definition of Case Study. PressAcademia 2018. https://www.pressacademia.org/definition-of-case-study/ (accessed March 8, 2019).

27. Weiss $\mathrm{CH}$. Nothing as Practical as Good Theory: Exploring Theory-Based Evaluation for Comprehensive Community Initiatives for Children and Families. 1994.

28. Forero R, Nahidi S, De Costa J, Mohsin M, Fitzgerald G, Gibson N, et al. Application of four-dimension criteria to assess rigour of qualitative research in emergency medicine. BMC Health Serv Res 2018;18. https://doi.org/10.1186/s12913-018-2915-2.

29. Saunders B, Sim J, Kingstone T, Baker S, Waterfield J, Bartlam B, et al. Saturation in qualitative research: exploring its conceptualization and operationalization. Qual Quant. 2018;52:1893-907. https://doi.org/10.1007/s11135-017-0574-8.

30. Michel J, Obrist B, Bärnighausen T, Tediosi F, McIntryre D, Evans D, et al. What we need is health system transformation and not health system strengthening for universal health coverage to work: Perspectives from a National Health Insurance pilot site in South Africa. South Afr Fam Pract. 2020;62:15. https://doi.org/10.4102/safp.v62i1.5079.

31. Michel J, Datay MI, Motsohi TJ, Bärnighausen T, Tediosi F, Mclntyre D, et al. Achieving universal health coverage in sub-Saharan Africa: the role of leadership development. J Glob Health Rep. 2020;4:e2020037. https://doi.org/10.29392/001c.12855.

32. INTERACTION | meaning in the Cambridge English Dictionary. n.d. https://dictionary.cambridge.org/dictionary/english/interaction (accessed January 31, 2019).

33. Michel J, Evans D, Tediosi F, deSavigny D, Egger M, Bärnighausen T, et al. Lest we forget, primary health care in Sub-Saharan Africa is nurse led. Is this reflected in the current health systems strengthening undertakings and initiatives? J Glob Health Rep 2018;2. https://doi.org/10.29392/joghr.2.e2018009.

34. Bressers JTA. From public administration to policy networks: Contextual interaction analysis. Rediscovering Public Law Public Adm Comp Policy Anal Tribute Peter Knoepfel 2009:123-42. 
35. Africa doesn't. need charity, it needs good leadership. World Econ Forum n.d. https://www.weforum.org/agenda/2017/05/africa-doesn-t-need-charity-it-needs-good-leadership/ (accessed January 18, 2019).

36. Leader. 9 major problems facing South Africa - and how to fix them I Leader.co.za 2011. http://www.leader.co.za/article.aspx?s=1\&f=1\&a=2893 (accessed September 20, 2018).

37. Leadership. Management \& Governance | Management Sciences for Health 2019. /our-work/healthsystem/leadership-management-governance (accessed July 30, 2019).

38. Curry L, Taylor L, Chen PG-C, Bradley E. Experiences of leadership in health care in sub-Saharan Africa. Hum Resour Health. 2012;10:33. https://doi.org/10.1186/1478-4491-10-33.

39. Chen T-Y. Medical leadership: An important and required competency for medical students. Tzu-Chi Med J. 2018;30:66-70. https://doi.org/10.4103/tcmj.tcmj_26_18.

40. Gilson L, Agyepong IA. Strengthening health system leadership for better governance: what does it take? Health Policy Plan. 2018;33:ii1-4. https://doi.org/10.1093/heapol/czy052.

41. Final Ideal Clinic Manual. - version 18 (26 July 2018).pdf n.d.

42. Do you believe. health is a human right? Then you believe in Universal Health Coverage - MMI n.d. http://www.medicusmundi.org/contributions/news/2018/do-you-believe-health-is-a-human-rightthen-you-believe-in-universal-health-coverage (accessed January 30, 2019).

43. Mala P, Zuber P, Politi C, Paccaud F. Ideal and reality: do countries adopt and follow recommended procedures in comprehensive multiyear planning guidelines for national immunization programmes? Implement Sci. 2015;10:48. https://doi.org/10.1186/s13012-015-0239-8.

44. Health Systems Trust (South Africa). South African health review 2011. Durban: Health Systems Trust; 2011.

45. Michel J, Tediosi F, Egger M, Barnighausen T, Mclntyre D, Tanner M, et al. Universal health coverage financing in South Africa: wishes vs reality. J Glob Health Rep. 2020;4:e2020061. https://doi.org/10.29392/001c.13509.

\section{Figures}




\begin{tabular}{|c|c|}
\hline $\begin{array}{c}\text { Information + } \\
\text { District actors-know what NHI is but not } \\
\text { sure of pilot meaning } \\
\text { Some subdistrict actors know NHI meaning } \\
\text { most are not sure } \\
\text { PHC actors not sure of NHI meaning nor } \\
\text { their roles in NHI }\end{array}$ & $\begin{array}{l}\text { Motivation----- } \\
\text { District actors fairly motivated } \\
\text { Subdistrict and PHC staff intrinsically motivated } \\
\text { District, Subdistrict and PHC staff demotivated by } \\
\text { lack of resources, support and unresolved } \\
\text { challenges impeding policy implementation }\end{array}$ \\
\hline $\begin{array}{l}\text { Power ---- } \\
\text { District actors, subdistrict and PHC actors all } \\
\text { have limited decision making power } \\
\text { None annot hire personnel } \\
\text { Disrtict and subdistrict actors have access to } \\
\text { a limited budget } \\
\text { PHC facility actors have no access to a budget }\end{array}$ & $\begin{array}{c}\text { Interactions ---- } \\
\text { District actor have to send motivations and staff } \\
\text { requests to province } \\
\text { Subdistrict and PHC facility actors get erratic } \\
\text { support visits from PHC supervisors } \\
\text { Interactions not helpful as problems remain } \\
\text { unresolved }\end{array}$ \\
\hline
\end{tabular}

Figure 1

Policy Maker CIT tenets

\section{Actor 1: Policy \\ Maker Actor Provincial level}

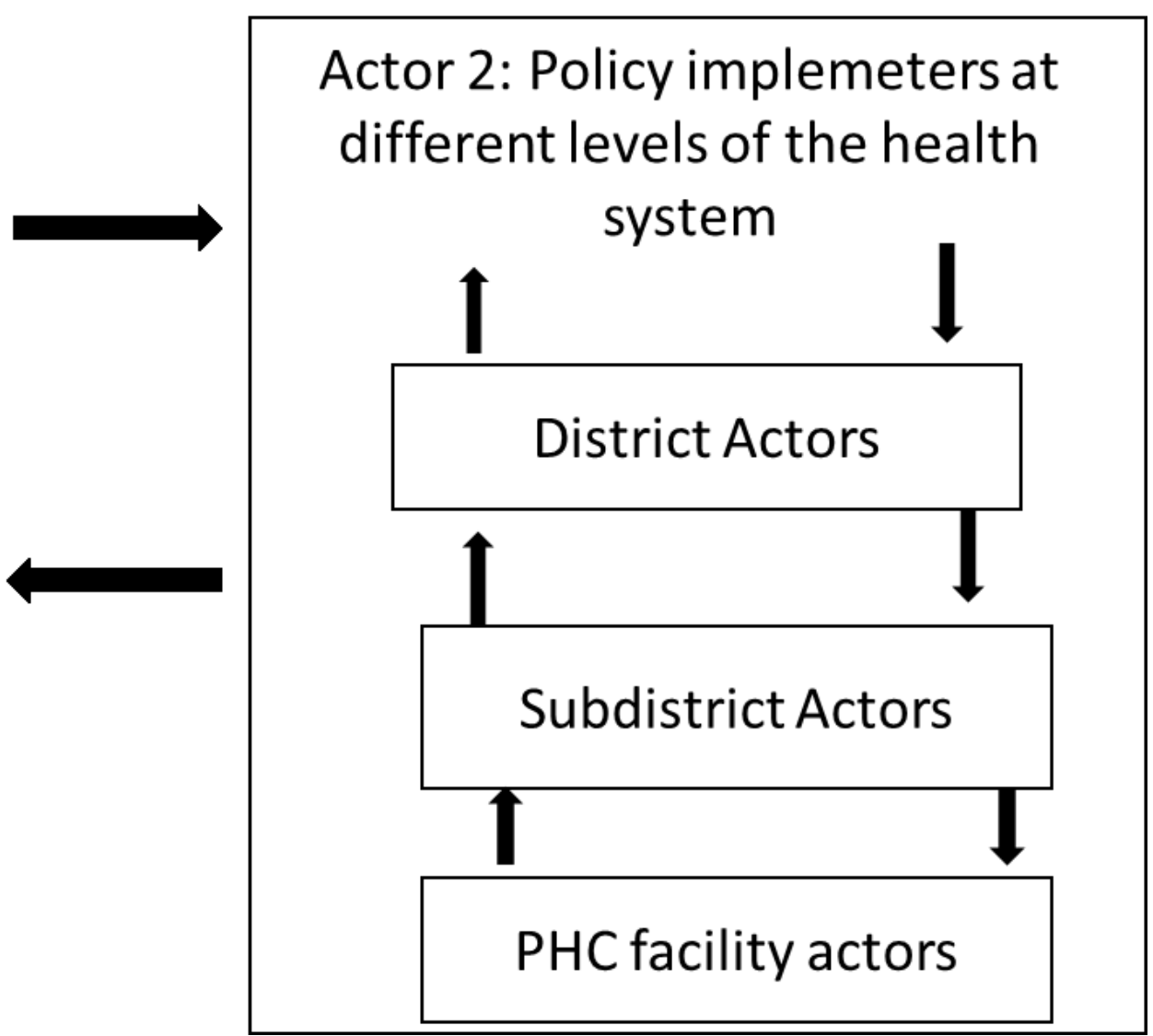


Figure 2

Interaction process

\section{Policy making actor}

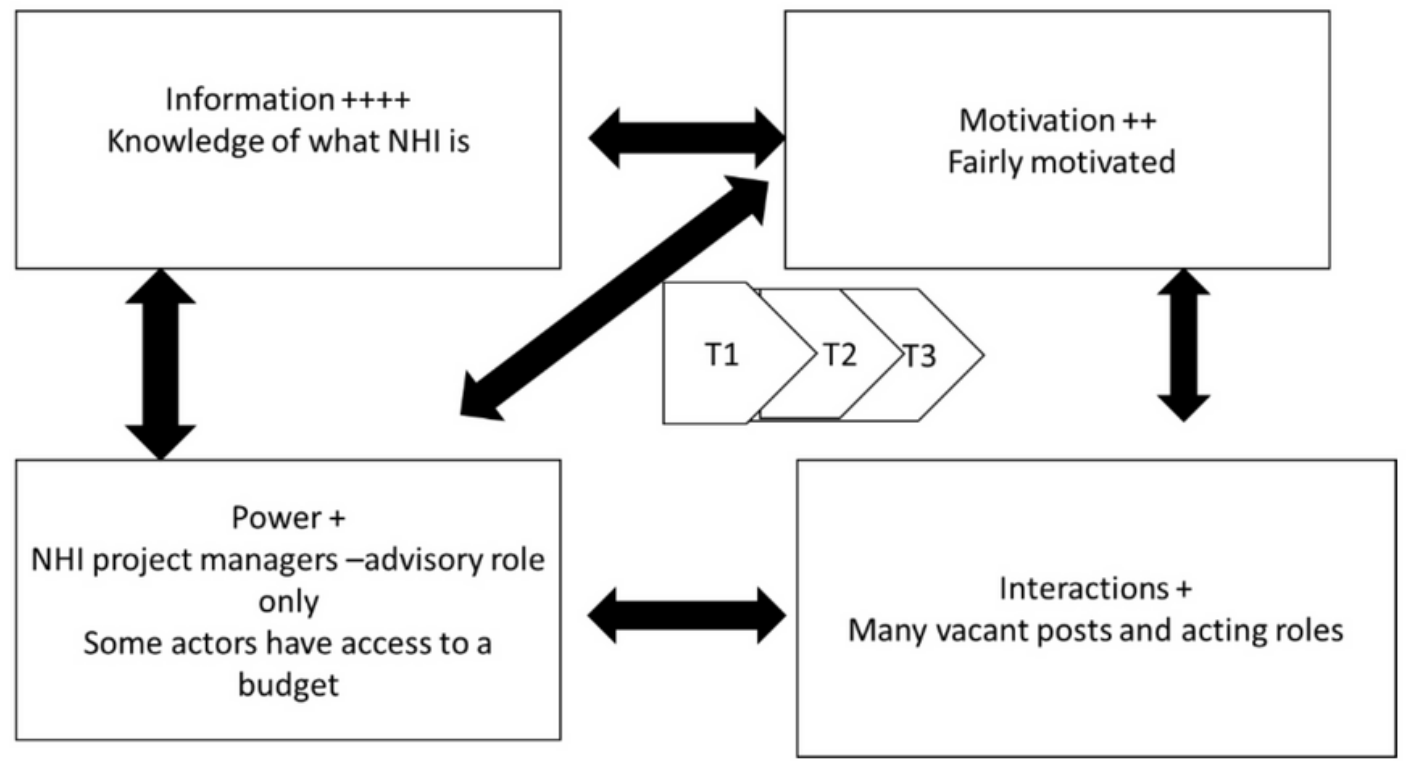

Figure 3

Policy Maker CIT tenets 


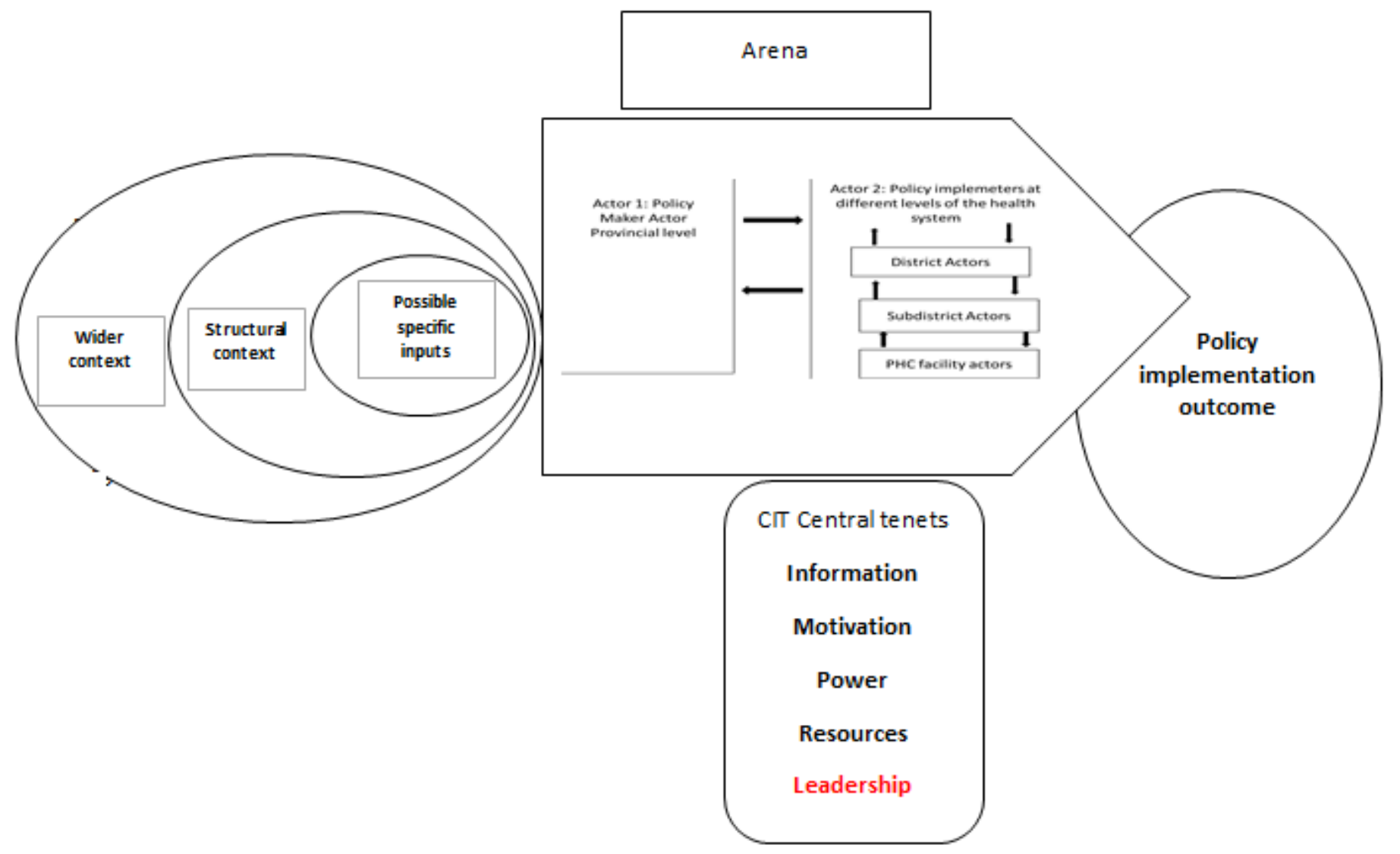

Adapted.

Source:

https://essav.utwente. $n 1 / 70753 / 1 /$ Pavlovic MA Facultv\%20of\%20Behavioral,\%20Management $\% 20$ n

d\%20Social\%20Sciences.pdf

\section{Figure 4}

The modified CIT process model which includes the fourth construct Leadership

\section{Supplementary Files}

This is a list of supplementary files associated with this preprint. Click to download.

- TIDieRChecklistWordfilled.docx 